\title{
Prothymosin alpha: a ubiquitous polypeptide with potential use in cancer diagnosis and therapy
}

\author{
Kyriaki Ioannou • Pinelopi Samara $\cdot$ Evangelia Livaniou • \\ Evelyna Derhovanessian · Ourania E. Tsitsilonis
}

Received: 8 November 2011 / Accepted: 10 February 2012

(c) Springer-Verlag 2012

\begin{abstract}
The thymus is a central lymphoid organ with crucial role in generating $\mathrm{T}$ cells and maintaining homeostasis of the immune system. More than 30 peptides, initially referred to as "thymic hormones," are produced by this gland. Although the majority of them have not been proven to be thymus-specific, thymic peptides comprise an effective group of regulators, mediating important immune functions. Thymosin fraction five (TFV) was the first thymic extract shown to stimulate lymphocyte proliferation and differentiation. Subsequent fractionation of TFV led to the isolation and characterization of a series of immunoactive peptides/polypeptides, members of the thymosin family. Extensive research on prothymosin $\alpha$ (proT $\alpha)$ and thymosin $\alpha 1$ (T $\alpha 1)$ showed that they are of clinical significance and potential medical use. They may serve as molecular markers for cancer prognosis and/or as therapeutic agents for treating immunodeficiencies, autoimmune diseases and malignancies. Although the molecular mechanisms underlying their effect are yet not fully elucidated,
\end{abstract}

K. Ioannou $\cdot$ P. Samara $\cdot$ O. E. Tsitsilonis $(\bowtie)$

Department of Animal and Human Physiology,

Faculty of Biology, University of Athens, Panepistimiopolis,

15784 Athens, Greece

e-mail: rtsitsil@biol.uoa.gr

E. Livaniou

Immunopeptide Chemistry Lab, Institute of Radioisotopes and Radiodiagnostic Products, National Centre for Scientific Research "Demokritos", Patriarchou Gregoriou and Neapoleos, Aghia Paraskevi, 15310 Athens, Greece

\section{E. Derhovanessian}

Tübingen Ageing and Tumour Immunology Group,

Center for Medical Research, University of Tübingen

Medical School, Waldhörnlestr. 22, 72072 Tübingen, Germany
proT $\alpha$ and $T \alpha 1$ could be considered as candidates for cancer immunotherapy. In this review, we will focus in principle on the eventual clinical utility of proT $\alpha$, both as a tumor biomarker and in triggering anticancer immune responses. Considering the experience acquired via the use of $\mathrm{T} \alpha 1$ to treat cancer patients, we will also discuss potential approaches for the future introduction of $\operatorname{proT} \alpha$ into the clinical setting.

Keywords Thymic peptides - Prothymosin $\alpha$. Thymosin $\alpha 1$. Anticancer therapy · Tumor markers

$\begin{array}{ll}\text { Abbreviations } & \\ \text { AAK cells } & \text { Anti-CD3-activated killer cells } \\ \text { BRM } & \text { Biologic response modifier } \\ \text { CDDP } & \text { Cisplatin } \\ \text { CML } & \text { Cell-mediated lympholysis } \\ \text { CTL } & \text { Cytotoxic T lymphocyte(s) } \\ \text { CY } & \text { Cyclophosphamide } \\ \text { DC } & \text { Dendritic cell(s) } \\ \text { DL } & \text { Dalton's lymphoma } \\ \text { DTIC } & \text { Dacarbazine } \\ \text { 5-FU } & \text { 5-Fluorouracil } \\ \text { HMGB1 } & \text { High mobility group box 1 } \\ \text { HSP } & \text { Heat sock protein } \\ \text { IFN } & \text { Interferon } \\ \text { IL } & \text { Interleukin } \\ \text { LAK cells } & \text { Lymphokine-activated killer cells } \\ \text { 3LL carcinoma } & \text { Lewis lung carcinoma } \\ \text { MHC } & \text { Major histocompatibility complex } \\ \text { NK cells } & \text { Natural killer cells } \\ \text { NSCL cancer } & \text { Non-small cell lung cancer } \\ \text { pI } & \text { Isoelectric point } \\ \text { PBL } & \text { Peripheral blood lymphocyte(s) } \\ \text { PBMC } & \text { Peripheral blood mononuclear cell(s) } \\ & \end{array}$




$\begin{array}{ll}\text { PGE2 } & \text { Prostaglandin E2 } \\ \text { PMN } & \text { Polymorphonuclear(s) } \\ \text { ProT } \alpha & \text { Prothymosin alpha } \\ \text { s.c. } & \text { Subcutaneous } \\ \text { TACE } & \text { Transarterial chemoembolization } \\ \text { TAM } & \text { Tumor-associated macrophages } \\ \text { T } \alpha 1 & \text { Thymosin alpha 1 } \\ \text { T } \beta 4 & \text { Thymosin beta } 4 \\ \text { TFV } & \text { Thymosin fraction V } \\ \text { TLR } & \text { Toll-like receptor(s) } \\ \text { TNF } & \text { Tumor necrosis factor } \\ \text { VP-16 } & \text { Etoposide }\end{array}$

\section{Introduction}

The thymus gland as a central lymphoid organ plays a crucial role in developing, maturing and differentiating many of the cellular components of the immune system and is considered essential for normal immune function. Until the early $60 \mathrm{~s}$, the gland was thought to be vestigial. At this time, its importance was documented by reports showing that the immune system of neonatally thymectomized rodents was generally crippled and an incapability to resist infections and histoincompatible transplants was noted [1-3]. The gland's involution with age results in a decrease of the levels of thymus-derived hormones [4] and a deficiency in immune reactivity, accompanied by an increase in cancer incidence and age-related diseases [5]. Thus, research efforts focused on the detection and identification of thymic humoral messages, namely complex thymic fractions and a series of structurally defined peptides [5].

Goldstein and colleagues were the first to report the purification of a thymic extract that stimulated lymphocytopoiesis and enhanced in vivo immune cell proliferation in mouse lymph nodes [6]. A year later, this lymphocytopoietic factor was purified, chemically characterized and given the name "thymosin" [7]. Subsequently, Goldstein's research team succeeded in further purifying a highly active preparation from bovine thymus, termed thymosin fraction $\mathrm{V}$ (TFV). In order to produce sufficient quantities of this fraction and thus explore TFV's properties, a new method, including 5 sequential steps of heat treatment, acetone and ammonium sulfate precipitation, ultrafiltration and gel filtration, was developed [8].

When tested in vivo, TFV and its component parts were able to enhance immune functions in newborn mice and to augment the survival of mice that had undergone thymectomy [9]. A similar activity was demonstrated in vitro in lymphocytes of immune-suppressed humans, where TFV restored, to almost normal levels, their deficient immune responses [10]. In addition, Dauphinee and colleagues reported that TFV administration in animals with autoim- mune diseases resembling human lupus erythematosus led to the retreat of some of the symptoms [11]. Finally, TFV was shown to exert in vitro antiproliferative effects in several neoplastic cell lines, including murine neuroendocrine pituitary adenoma and glioma [12], human acute T lymphoblastic [13] and promyelocytic leukemias [14]. In animals, treatment with TFV conferred resistance to Dunning [15] and murine lymphoblastic leukemias [16].

All these in vivo and in vitro immunomodulatory properties of TFV became the pretext for further investigating and analyzing its components. Efforts toward this direction showed that TFV consisted of 10-15 basic components and 20 or more secondary ones, with molecular weights varying between 1,000 and 15,000 Da. A system of nomenclature was developed to distinguish and characterize the individual peptides in TFV. These were consequently divided into three groups (identified by the Greek letters alpha $[\alpha]$, beta $[\beta]$ and gamma $[\gamma])$, according to their isoelectric point (pI). Group $\alpha$ comprised peptides with $\mathrm{pI}<5$, group $\beta$ those with pI between 5 and 7 and group $\gamma$ peptides with $\mathrm{pI}>7$. Peptides from each group were, and still are, indicated with a subscript, 1, 2, 3, etc., that denotes the order of their isolation and identification from TFV. Depending on whether they are biologically active or not, they are further characterized as thymosins or simple peptides/polypeptides, respectively [17].

The majority of the polypeptides, isolated so far from TFV, belong to $\alpha$ - and $\beta$-thymosins, whereas none of them belong to $\gamma$-thymosins. The family of $\alpha$-thymosins is mainly represented by thymosin $\alpha 1$ (T $\alpha 1)$, a 28 -amino acid peptide that was the first member of this family isolated from TFV and prothymosin $\alpha$ (proT $\alpha$ ), a 109-112 amino acid long polypeptide (depending on the mammalian species), proven to be T $\alpha$ l's precursor molecule, and the natural polypeptide present within the cells [18]. Thymosin $\beta 4(\mathrm{~T} \beta 4)$ is the major representative of the $\beta$-thymosin family [19]. T $\beta 4$ along with proT $\alpha$ retains the major activity of TFV and this is the main reason why, more than 25 years after their isolation, they are still in the scientific spotlight (Table 1).

The dual—intracellular and extracellular-role of proT $\alpha$

Although initially referred to as a "thymic hormone," proT $\alpha$ demonstrates some unique properties: it is not thymus-specific, as it is encountered in many lymphoid, but also nonlymphoid organs [20]; it is highly conserved during evolution, as it presents extended homology in its primary structure among mammalian species [19]; and it is a universal polypeptide surmounting approximately 10,000 copies per cell [21]. The ubiquitous and wide distribution of $\operatorname{proT} \alpha$ in tissues and cells implied its participation in important cellular molecular circuits. Accumulating evidence available to date suggests a dual role for the polypeptide: in the 
Table 1 Major representatives of structurally characterized $\alpha$ - and $\beta$-thymosins

\begin{tabular}{lllll}
\hline Thymosin & $\begin{array}{l}\text { Year of isolation/ } \\
\text { identification }\end{array}$ & $\begin{array}{l}\text { Number of } \\
\text { amino acids }\end{array}$ & Localization & Ref. \\
\hline $\begin{array}{l}\alpha \text {-Thymosins } \\
\text { Thymosin } \alpha 1\end{array}$ & 1966 & 28 & Ubiquitous, cytoplasm, serum, urine & [7] \\
$\begin{array}{l}\text { Prothymosin } \alpha \\
\text { Parathymosin } \alpha\end{array}$ & 1984 & $109-112$ & Ubiquitous, nucleus, cytoplasm, serum, urine & {$[18]$} \\
$\beta$-Thymosins & & 101 & Ubiquitous, nucleus, cytoplasm, serum & [19] \\
Thymosin $\beta 4$ & 1979 & & & \\
Thymosin $\beta 9$ & 1982 & 44 & Ubiquitous, nucleus(?), cytoplasm, serum & [19] \\
Thymosin $\beta 10$ & 1983 & 42 & Ubiquitous in calf, cytoplasm & [19] \\
\hline
\end{tabular}

cell, proT $\alpha$ controls the cell cycle, whereas extracellularly, the polypeptide exerts an immunomodulatory effect.

We now know that proT $\alpha$ is crucial for the survival and proliferation of normal cells [21]. Several reports have demonstrated that proT $\alpha$ mRNA increases in lymphocytes $[21,22]$ and in NIH3T3 cells stimulated to divide [23], and proT $\alpha$ antisense oligomers inhibit myeloma cell-division [24]. ProT $\alpha$ prevents apoptosis through inhibiting apoptosome formation [25], regulates DNA remodeling during proliferation, controls gene expression by directly binding to free-core histone H1 [26] and increases the accessibility of micrococcal nuclease to chromatin [27]. An association between the oncogene $c$-myc and proTa has also been reported; Eilers and coworkers showed that activation of $c$-myc in quiescent rat and mouse fibroblasts led to rapid increase in transcription of proT $\alpha$ and elicited reentry into and progression through the cell cycle [28]. Most recently, proT $\alpha$-mediated nuclear import of Keap1, an inhibitor of the stress-sensor Nrf2, was proposed as a novel mechanism promoting cell survival [29].

Extracellularly, it has been suggested that proT $\alpha$ acts as a biologic response modifier (BRM) stimulating immune responses. The initial observations came from in vivo studies in animals, where proT $\alpha$ was able to protect immunosuppressed mice against infections caused by Candida albicans and other opportunistic infections [30]. When added in lymphocyte cultures, proT $\alpha$ enhanced antigen or mitogen-induced $\mathrm{T}$ cell proliferation, increased the production of interleukin (IL)-2 and the expression (both in number and in density) of its receptor on T cells [31, 32] and upregulated major histocompatibility complex (MHC) class II antigen expression on human monocytes [33]. ProT $\alpha$ was also shown to stimulate the cytotoxicity of natural killer (NK) cells [34] and the induction of lymphokine-activated killer (LAK) cells activity [35]. To clarify the molecular mechanisms underlying these immunomodulatory functions, Cordero and colleagues used radioiodinated, biologically active proT $\alpha$ to study the binding sites of the molecule on human lymphoblasts [36]. Two binding sites, of low and high affinity, were identified, both of which were specific for $\operatorname{proT} \alpha$, but not $T \alpha 1$. In a subsequent study, Piñeiro and colleagues revealed three binding "partners" for proT $\alpha$ in the membrane of lymphoblasts, which formed a cap-like structure on one of the cell's poles and associated with lipid rafts $[37,38]$. Most recently, proT $\alpha$ was suggested to ligate toll-like receptor (TLR)-4, signal through the TRIF-dependent pathway and induce interferon (IFN)- $\beta$ production [39]. The concept currently under investigation is that proT $\alpha$ functions as an alarmin, which when experimentally proven would explain the proT $\alpha$-induced activation of innate and adaptive immunity [40] and provide a link between the two discrete functions of the molecule.

Nevertheless, in view of the two aforementioned activities of $\operatorname{proT} \alpha$, over the years, several research groups have explored the possibility that the polypeptide may serve as a molecular marker for cancer prognosis and/or as a therapeutic agent for treating immunodeficiencies, autoimmune diseases and malignancies [41]. Herein, we will review data acquired with respect to proT $\alpha$ 's (in comparison with T $\alpha 1$ ) potential use as a cancer biomarker and as an option in the treatment of cancer.

ProT $\alpha$ as a cancer (bio)marker. Use in cancer diagnosis/ prognosis

ProT $\alpha$ is probably the most well-studied thymosin with respect to its relevance to malignant cell transformation, and several studies have been carried out to investigate the levels of proT $\alpha$ in a variety of cancer cells.

In view that cancer cells are highly proliferative, it was not surprising to detect high proT $\alpha$ content, both at mRNA and protein level, in malignant tissues. With respect to the former, in rats, high proT $\alpha$ mRNA expression was detected in mitogen-stimulated thymocytes and splenic $\mathrm{T}$ cells [42], in proliferating pituitary tumors [43] and during the initial stage (first 6 weeks) of hepatic carcinogenesis, where proT $\alpha$ mRNA remained almost tenfold higher as the neoplasm progressed. In situ hybridization revealed that overexpressed proT $\alpha$ mRNA was restricted to neoplastic nodules in the hepatic tissue and to tumor cells invading blood vessels [44]. 
Table 2 Prothymosin $\alpha$ as a biomarker for cancer prognosis in humans

\begin{tabular}{|c|c|c|c|}
\hline Type of cancer & Material detected & Correlation with & Ref. \\
\hline Bladder & Protein in tissue and urine & Cancer detection; cancer grade; follow-up & {$[58,67]$} \\
\hline Breast & Protein in tissue and serum & $\begin{array}{l}\text { Cancer grade; tumor recurrence; } \\
\text { lymph node metastasis; distant metastases; } \\
\text { risk of death; overall survival }\end{array}$ & {$[52-55,65]$} \\
\hline Colon & mRNA in tissue & $c$-myc expression & {$[45,52]$} \\
\hline Gastric & Protein in tissue & - & {$[63]$} \\
\hline Head and neck & Protein in tissue & Tumor recurrence & {$[62]$} \\
\hline Liver & mRNA in tissue; protein in tissue & $c-m y c$ expression; poor prognosis & {$[46,60]$} \\
\hline Lung & mRNA in tissue & Poor prognosis & {$[48]$} \\
\hline Neuroblastoma & mRNA in tissue & $N$-myc expression & {$[47]$} \\
\hline Pituitary & Protein in tissue & Tumor recurrence & {$[61]$} \\
\hline Prostate & Protein in tissue & Cancer cell differentiation; tumor progression & {$[56,57]$} \\
\hline Rectal & mRNA in tissue & Effectiveness of radiotherapy & {$[51]$} \\
\hline Rhabdomyosarcoma & mRNA in tissue & - & [49] \\
\hline Thyroid & $\begin{array}{l}\text { mRNA in tissue; } \\
\text { protein in tissue and serum }\end{array}$ & Cancer cell differentiation & {$[50,66]$} \\
\hline Upper urinary tract & Protein in tissue & Tumor recurrence & {$[59]$} \\
\hline
\end{tabular}

In humans, high proT $\alpha$ mRNA levels were correlated with those of $c$-myc in colon [45] and liver cancer [46] and $N$-myc in neuroblastoma [47] (Table 2). However, although lung cancer tissues showed similarly elevated proT $\alpha$ mRNA expression, this was not paralleled by c-myc mRNA increase [48], indicating that simultaneous transcription of the two genes does not occur in all cancer types. In the last report, the possibility of using proT $\alpha$ levels as a biomarker was proposed, as high proT $\alpha$ mRNA was associated with poorer prognosis of lung cancer patients. ProT $\alpha$ mRNA was also found significantly elevated in rhabdomyosarcoma [49] and in well-differentiated thyroid carcinomas compared to thyroid adenomas and goiters [50]. By developing a highly sensitive real-time polymerasechain reaction assay able to determine proT $\alpha$ levels in very small samples, such as those acquired through fine-needle aspiration, the authors suggested the potential usage of $\operatorname{proT} \alpha$ as a novel proliferation marker for cancer development. From another aspect, of particular interest is the study of Ojima and coworkers [51], which opens new prospects for the use of the polypeptide in the clinic: upregulation of proT $\alpha$ mRNA in rectal cancer, predicts resistance to and effectiveness of radiotherapy.

At the protein level, results from cancer tissues verified the fact that aggressive tumors contain more proT $\alpha$. We showed that proT $\alpha$ levels, as quantified by highly sensitive and specific radioimmunoassays for the amino- and the carboxy-termini of the polypeptide, were highly elevated in breast and colon cancers compared to the nearby healthy tissues [52]. At the same time, Dominguez and coworkers confirmed our observation, reporting high proT $\alpha$ content in primary ductal carcinomas of the breast [53], and went further correlating tumor proT $\alpha$ levels with disease outcome. Specifically, they estimated that patients with cancer tissue proT $\alpha$ content over $124 \mathrm{ng} / \mathrm{mg}$ had a higher probability of developing distant metastases.

The clinical significance of these findings was next investigated. The aforementioned research teams showed that expression of proT $\alpha$ in human breast cancer (a) depends on the proliferation status of the tumor [54], (b) is associated with already established prognostic factors describing the metastatic potential of the tumor [54], (c) predicts the rate of tumor recurrence [55] and (d) relates to the overall survival of the patient $[54,55]$. Therefore, both studies, although performed independently, came to the same conclusion that high proT $\alpha$ levels in primary breast tumors can be considered as an early "sign" correlated with a worse outcome of the disease.

Later on, Suzuki and colleagues studied proT $\alpha$ expression with respect to the differentiation and progression of human prostate cancers. By immunohistochemistry and immunoblotting, they showed that proT $\alpha$ levels consecutively increased as prostate tissue progressed from normal epithelium, through prostatic intraepithelial neoplasia to carcinoma [56]. Particularly, in prostate cancer lesions, intense nuclear staining for proT $\alpha$ was also reported [57]. Subsequent complementary research investigated proT $\alpha$ expression in human bladder cancer using tissue microarrays [58]. A statistically significant enhancement of proT $\alpha$ expression, also from the clinical aspect, was 
recorded in bladder tumors compared with their normal adjacent tissues, which was most prominent in tumors of a higher grade. In upper urinary tract cancer, tumor recurrence was associated with proT $\alpha$ overexpression, but only when the polypeptide was localized in the tumor-cell cytoplasm [59]. These findings support the potential usage of $\operatorname{proT} \alpha$ as a diagnostic tool, maybe also as a therapeutic target, for cancers of the urinary tract. Finally, immunostaining of hepatocellular carcinomas [60], pituitary tumors [61] and head and neck carcinomas [62], but not of gastric cancers [63], associated high proT $\alpha$ content with aggressive tumors and poor prognosis.

As proT $\alpha$ is an intracellular protein, studies to reveal its relevance to cancer were performed until recently in malignant tissues and their extracts. Such analysis of proT $\alpha$ content has the advantage of directly "viewing" the mRNA or protein content of the tumor itself, but also has the main disadvantage that sufficient amounts of tissue are not always available. In principle, cancer biomarkers are determined in biologic fluids, usually blood plasma/serum or urine. Indeed, soon after its identification, proT $\alpha$ was detected in human blood [64], its presence attributed either to leakage from damaged leukocytes or "secretion" from proT $\alpha$-rich cells via an as yet unknown mechanism. Nevertheless, to date, proT $\alpha$ detection in cancer patients' sera is reported in only two studies (a) in breast cancer patients [65] and (b) in a secretome analysis of thyroid carcinomas [66]. Unfortunately, no correlation of blood $\operatorname{proT} \alpha$ levels with cancer development and/or prognosis was found.

However, an interesting report revealed that urine $\operatorname{proT} \alpha$ has the potential of being a useful tumor marker for the detection and follow-up of bladder cancer [67]. Urine samples, obtained from healthy volunteers, patients with urinary infection or bladder transitional and non-transitional cell carcinomas, were assayed for their proT $\alpha$ levels by a specific enzyme-linked immunosorbent assay. Subsequent comparison of the results showed that (a) urine $\operatorname{proT} \alpha$ was higher in newly diagnosed bladder cancer patients, (b) patients with non-transitional cell carcinoma tumors had lower proT $\alpha$ in their urine compared to patients with bladder tumors, and (c) during a 3-month follow-up, urine $\operatorname{proT} \alpha$ content increased when residual or a recurrent tumor was present after treatment. Although the cross-reactive material present in urine was not identified as intact $\operatorname{proT} \alpha$, this study opens new perspectives for the introduction of $\operatorname{proT} \alpha$ as a novel cancer marker in the clinic, particularly for urinary tract carcinomas (Table 2).

The use of $\mathrm{T} \alpha 1$ as a cancer biomarker

As already mentioned, T $\alpha 1$ was the first $\alpha$-thymosin isolated, and therefore, its relevance to human disease, includ- ing cancer, was investigated early on. In contrast to the study of proT $\alpha$ expression mainly in cancer tissues, $T \alpha 1$ content was investigated, almost exclusively, in plasma of patients with cancer. In the initial report by Hersh and colleagues [68], plasma $T \alpha 1$ levels were higher in patients with various solid tumors, hematologic malignancies and immunodeficiencies. In lung cancer patients, mean $T \alpha 1$ plasma levels, as determined by a sensitive radioimmunoassay specific for $T \alpha 1$, were elevated compared to normal individuals, suggesting that plasma $T \alpha 1$ could be used as a biomarker for lung cancer prognosis [69]. Further investigations aimed at determining the role of $\mathrm{T} \alpha 1$ in lung cancer revealed that its levels correlated neither with the stage nor the pathological subtype of the cancer. Similarly, patients with gastric cancer had elevated plasma $T \alpha 1$, which did not correlate with the clinical stage of the disease [70]. Nevertheless, plasma $T \alpha 1$ was higher in patients with lymph node metastases that stained positive for $T \alpha 1$. The latter finding led the authors to conclude that higher $\mathrm{T} \alpha 1$ expression may be related to the more aggressive nature of the tumor.

It is of interest to note that the relevance of $T \alpha 1$ levels with cancer development and/or prognosis is not as established as that of proT $\alpha$. In our opinion, this observation is reasonable and results from the fact that the natural polypeptide, present intracellularly and participating in cell proliferative events, either normal or abnormal, is proT $\alpha$ [52]. Consequently, the presence of $\mathrm{T} \alpha 1$ in malignant tissues or in cancer patients' plasma could be either the result of extensive proT $\alpha$ cleavage and release, possibly associated with uncontrolled cancer cell growth, or the outcome of a randomly produced by-product of abnormal processes often seen in malignant lesions.

\section{A-thymosins in cancer therapy}

During the last decade, scientific interest has turned toward therapies that may restore immunity under conditions of immune-suppression associated with cancer, based on the assumption that a strong immune response will result in successful tumor growth inhibition. Among other thymic peptides tested alone or in combination with other BRMs such as cytokines, proT $\alpha$ and $T \alpha 1$ have been suggested as candidate molecules for cancer immunotherapy. Actually, synthetic $T \alpha 1$ formulated for subcutaneous (s.c.) injection (thymalfasin), under the trade name Zadaxin (SciClone Pharmaceuticals) [71], is the only $\alpha$-thymosin widely tested in the clinical setting in humans for over 25 years, for the treatment of a variety of diseases, from cancer to viral infections and AIDS. Because of its excellent safety record, Zadaxin is currently approved in over 30 countries worldwide, as an immunostimulant. The drug is proposed to act by increasing the expression of MHC class I molecules, the numbers of $\mathrm{CD} 4+, \mathrm{CD} 8+\mathrm{T}$ and $\mathrm{NK}$ cells and the 
production of IL-2 and IFN- $\gamma$, while reducing T cell apoptosis and decreasing IL-4 and IL-10 production.

$\operatorname{ProT} \alpha$ as an immunotherapeutic tool

As already stated, proT $\alpha$ exhibits some intriguing extracellular properties and is now classified in the family of BRMs. In the early 90s, evidence with respect to the anticancer potential of $\operatorname{proT} \alpha$ came to light, although the mode of action of the polypeptide still remained obscure (Table 3). ProT $\alpha$ 's efficacy was studied in three successive reports in an aggressive in vivo animal tumor model. Specifically, therapeutic administration of proT $\alpha$ (ca. $3 \mu \mathrm{g} /$ mouse over 3 weeks) in DBA/2 mice inoculated with syngeneic leukemic L1210 cells inhibited the development of ascites in $20 \%$ of the animals and prolonged the survival of $40-60 \%$ of them by several weeks compared to controls (10 vs 2 weeks, respectively) [72]. A potential mechanism of action of the polypeptide was linked to the activation of peritoneal exudate cells in proT $\alpha$-treated mice, since they were shown to produce six to eight times higher levels of tumor necrosis factor (TNF)- $\alpha$ and thus exhibit cytotoxicity against various cell lines, both TNF- $\alpha$-sensitive and TNF- $\alpha$ resistant. A detailed analysis of the immunological alterations induced upon proT $\alpha$ treatment was subsequently performed in the same animal model [73]. As expected, splenocytes from proT $\alpha$-treated mice exhibited significantly higher ex vivo cytotoxic activity against NK-sensitive and NK-resistant targets and most importantly against the syngeneic tumor cells. Indeed, proT $\alpha$ was shown to increase both the number and the activation level of NK and $\mathrm{CD} 3+\mathrm{T}$ cells, as well as of the $\mathrm{CD} 8+\mathrm{T}$ cell population. In vitro, proT $\alpha$-induced stimulation of splenocytes additionally revealed that lymphocyte proliferation and cytotoxicity were sustained by the high concentrations not only of TNF- $\alpha$ but also of IL-2 produced in response to $\operatorname{proT} \alpha$, and this most likely also occurs in vivo [74]. Of utmost importance was the observation that when proT $\alpha$ was administered in vivo simultaneously with the L1210 tumor cells, the polypeptide provoked the generation of tumor-specific CD8+ cytotoxic $\mathrm{T}$ lymphocytes (CTL), which, subsequently, lysed the syngeneic targets in a MHC-restricted fashion [74]. This enhanced CTL activity was supported by concomitantly induced L1210-specific CD4+ T cells and by the production of IL- 2 and TNF- $\alpha$ in the spleen, peritoneal cavity and probably other lymphoid organs. This last report clarified an important issue regarding the activity of $\operatorname{proT} \alpha$; mice receiving only proT $\alpha$ in principle developed nonMHC-restricted cytotoxic activity (mediated by NK and LAK cells), whereas mice concomitantly receiving proT $\alpha$ and L1210 tumor cells developed both MHC-restricted (CTL) and non-MHC-restricted cytotoxic activities and survived longer. The overall results suggest that in vivo,
proT $\alpha$ acts upstream lymphocyte activation and its mode of action is IL-2-dependant. Moreover, depending on the presence of tumor-specific antigenic peptides or not, $\operatorname{proT} \alpha$ can "manoeuver" anticancer immune responses shifting them toward the appropriate, most effective route of stimulation.

Following the studies in mice, the effect of proT $\alpha$ was next tested in humans (Table 3 ). Since cancer patients are generally characterized by decreased cytotoxic activity and dysfunction in lymphokine production, proT $\alpha$ 's ability to restore these deficiencies was investigated in vitro, using immune-impaired peripheral blood lymphocytes (PBL) from cancer-bearing individuals [75]. ProT $\alpha$ normalized, to a great extent, the significantly reduced cell-mediated lympholysis (CML) and NK cell activity, which were by definition much lower in patients with advanced malignancies of various types compared to normal individuals. This restoration of immune responses was attributed to the appropriate modification of the levels of prostaglandin E2 (PGE2) and IL-2, cytokines that were down- and up-regulated by proT $\alpha$, respectively. Accordingly, both CML and NK cell activity improved almost to normal, indicating that, in vitro, the polypeptide is capable of partially or even fully restoring cancer-induced immune deficiencies [75].

With respect to a specific type of cancer, results from a study in cells from melanoma patients showed that monocyte disorders could be partially normalized by proT $\alpha$ [76]. In fact, both normal donor- and melanoma patient-derived monocytes preincubated with $\operatorname{proT} \alpha$ alone or in the presence of IFN $-\gamma$ to enhance antigen presentation inhibited SK-MEL-28 melanoma cell growth in vitro. Moreover, monocytes from patients at earlier stages (I/II) of the disease showed higher tumoristatic activity than those at stage III and tended to respond better to preincubation with proT $\alpha$ followed by IFN- $\gamma$ activation. The restorative effect of proT $\alpha$ on the impaired activity of LAK cells derived from melanoma patients was additionally shown [77]. However, lymphocytes from individual patients demonstrated a broad range of LAK cell responsiveness to $\operatorname{proT} \alpha$, which was dependant, among other factors, on the stage of the disease; cells from patients with early stage I/II melanomas were those that responded better to proT $\alpha$ treatment in vitro.

The effect of proT $\alpha$ was also studied on PBL and monocytes derived from colorectal tumor patients [78-80]. Once more, proT $\alpha$ in synergy with IL-2 could efficiently stimulate patients' LAK cell activity only at early stages (Dukes $\mathrm{A} / \mathrm{B})$ of the disease $[78,80]$. ProT $\alpha$ acted via increasing the adhesion of lymphocytes to tumor targets (namely of SW620 colon carcinoma), and this effect was mediated by increased secretion of the deficient IL-2-induced IFN- $\gamma$. Phenotypic analysis of the proT $\alpha$ (in synergy with IL-2)activated lymphocytes revealed that the polypeptide enhanced the expression of CD56, CD16/56 on NK cells, of 
Table 3 Prothymosin $\alpha$ as a therapeutic agent for cancer treatment

\begin{tabular}{|c|c|c|c|}
\hline Cancer/species & Synergy with & Effect & Ref. \\
\hline \multicolumn{4}{|l|}{ In vitro } \\
\hline \multirow[t]{2}{*}{ Breast/human } & Anti-CD3 & Improvement of MHC- or non-MHC-restricted cytotoxicity & {$[81,86]$} \\
\hline & \pm fMLP & Increase of chemotaxis, oxidative responses and cytotoxicity of PMN & \\
\hline \multirow[t]{3}{*}{ Colorectal/human } & IL-2 & $\begin{array}{l}\text { Enhancement of LAK activity; increased expression of cytotoxic } \\
\text { surface molecules on NK, NKT-like cells and lymphocytes }\end{array}$ & {$[78-80,86]$} \\
\hline & $\pm \mathrm{IFN}-\gamma$ & $\begin{array}{l}\text { Decrease of monocyte-derived TGF- } \beta \text { and PGE } 2 \text { production; increase } \\
\text { of monocyte-derived IL- } 1 \beta \text { and TNF- } \alpha \text { production; monocyte-induced } \\
\text { colon cancer cell cytotoxicity }\end{array}$ & \\
\hline & \pm fMLP & Increase of chemotaxis, oxidative responses and cytotoxicity of PMN & \\
\hline Lung/human & Anti-CD3 & Improvement of MHC- or non-MHC-restricted cytotoxicity & [81] \\
\hline \multirow[t]{3}{*}{ Melanoma/human } & $\pm \mathrm{IFN}-\gamma$ & Enhancement of PBMC-induced melanoma cell cytotoxicity & {$[76,77,86]$} \\
\hline & IL-2 & Restoration of LAK cell activity & \\
\hline & \pm fMLP & Increase of chemotaxis, oxidative responses and cytotoxicity of PMN & \\
\hline Ovarian/human & Anti-CD3 & Improvement of MHC- or non-MHC-restricted cytotoxicity & [81] \\
\hline \multirow[t]{2}{*}{ Various tumors/human } & - & $\begin{array}{l}\text { Restoration of CML and NK cell activity; increase of PBMC-derived } \\
\text { IL-2 production; decrease of PBMC-derived PGE2 }\end{array}$ & {$[75,84]$} \\
\hline & IL-2 & Increase of $\mathrm{CD} 4+\mathrm{T}$ cell proliferation; generation of tumor-specific $\mathrm{CTL}$ & \\
\hline \multicolumn{4}{|l|}{ In vivo } \\
\hline \multirow[t]{3}{*}{ Leukemia/mouse } & - & Prolongation of survival & {$[72,74]$} \\
\hline & & $\begin{array}{l}\text { Enhancement of NK cell- and induction of LAK cell- activity } \\
\text { in splenic lymphocytes }\end{array}$ & {$[73]$} \\
\hline & & $\begin{array}{l}\text { Increase of TNF- } \alpha \text { production; induction of tumoricidal activity } \\
\text { by peritoneal exudate cells; selective expansion of leukemia-specific T cells }\end{array}$ & [74] \\
\hline
\end{tabular}

CD3/16/56 on NK-like T cells and of CD25, CD18 and CD11a on lymphocytes. Colon cancer patient-derived monocytes in vitro stimulated with proT $\alpha$ and/or IFN- $\gamma$ exhibited elevated average antitumor activity against SW620 colon carcinoma cells, paralleled by production and secretion of reduced concentrations of transforming growth factor- $\beta$ and PGE2 and increased levels of the proinflammatory cytokines IL- $1 \beta$ and TNF- $\alpha$, as determined in the culture supernatants $[79,80]$. The aforementioned results suggested that in vitro proT $\alpha$ can partially, however significantly, restore lymphocyte deficiencies present in cancer patients, by selectively regulating some functions of monocytes. The latter, in response to proT $\alpha$, secrete cytokines and create a suitable cytokine milieu facilitating lymphocyte activation. It should be noted that proT $\alpha$ 's activity highly depends on the stage of the disease, at least in melanoma and colon cancer patients, suggesting that the polypeptide can reverse mild but not severe tumor-induced immune-suppression.

A combination of two or more immunomodulatory molecules acting synergistically has often been shown to induce improved anticancer effects. Anti-CD3 monoclonal antibody has been reported to augment the cytotoxic functions of lymphocytes and has been successfully used for the large-scale expansion of non-MHC-restricted cytotoxic subsets for adoptive cellular immunotherapy, referred to as
anti-CD3-activated killer (AAK) cells. Baxevanis and coworkers combined anti-CD3 with $\operatorname{proT} \alpha$ and demonstrated that anti-CD3 plus proT $\alpha$ can improve AAK cytotoxicity of peripheral blood mononuclear cells (PBMC) derived from cancer patients with various malignancies, such as breast, ovarian and lung [81]. ProT $\alpha$ increased PBMC MHC- and non-MHC-restricted killing of tumor targets, but most importantly of autologous tumor cells by anti-CD3-activated CD8+ and CD56+ lymphocytes, implying that this thymic polypeptide might be active in vivo also.

Along the same line, combining proT $\alpha$ with low-dose IL-2 enhanced the induction of LAK cell activity [82], potentiating in particular the cytotoxicity of the CD16+ CD2- subset [83], whereas synergy between IL-2 and proT $\alpha$ increased the generation of tumor-specific cytotoxic $\mathrm{T}$ lymphocytes against autologous human carcinomas [84]. In the study of Voutsas and colleagues [84], PBMC obtained from cancer patients were cocultured in vitro with autologous tumor cells in mixed lymphocyte-tumor cultures in the presence of proT $\alpha$ and/or IL-2. The combination proT $\alpha / \mathrm{IL}-2$ increased the proliferation of CD4+ T cells and the generation of MHC class I-restricted autologous tumor-specific CTL. An important issue clarified by this study was that in order for proT $\alpha$ to exert its beneficial effect on CTL, the concomitant presence of autologous 
CD4+ T cells and monocytes in the cultures was required. Indeed, the absence of either subpopulation resulted in strong impairment of both proliferative and cytotoxic responses, which could not be reversed even if $\operatorname{proT} \alpha$ was added later on, suggesting that proT $\alpha$-stimulated responses demand initial collaborative interactions between CD4+, CD8+ T cells and antigen-presenting cells.

Our research team assembled this accrued data on the mode of action of proT $\alpha$ in a cellular model. We used proteomics to detect intracellular protein changes induced in mononuclear cells, derived either from normal donors or cancer patients, over the course of a 3-day stimulation with proT $\alpha$ [85]. Based on the identification of immunologically significant molecules overexpressed downstream $\operatorname{proT} \alpha$ activation, we proposed that initially, proT $\alpha$ triggers monocyte stimulation via TLR-ligation and signaling and enhances antigen presentation through MHC class II molecule upregulation. This event consequently promotes monocyte-T cell immune synapse. Subsequently, activated monocytes produce proinflammatory cytokines (IL-1), and highly activated, via $\mathrm{T}$ cell receptor triggering, $\mathrm{T}$ cells produce IL-2 and proliferate. Finally, proT $\alpha$-stimulated PBMC express high levels of surface integrins (CD2) and of intracellular cytotoxic molecules (perforin), both of which contribute to the enhancement of their cytotoxic activity. Our results are in agreement with most recent data, suggesting that proTa is an endogenous TLR-4 ligand, which can induce the production of type I IFNs from macrophages [39].

ProT $\alpha$ exerts multiple immunological activities in vitro, and with this in mind, proT $\alpha$ 's ability to enhance polymorphonuclear leukocyte (PMN) properties was also investigated [86]. ProT $\alpha$-stimulated PMN isolated from patients with colorectal, breast and melanoma tumors showed increased chemotaxis and enhanced oxidative responses. ProT $\alpha$-stimulated PMN became also more cytotoxic versus HCT-116 colon tumor target cells. The outcome of the latter study, in conjunction with the already analyzed effects of proT $\alpha$, implies that the polypeptide acts pleiotropically and is able to improve distinct functions of immune cells under particular conditions of immunosuppression.

Although extensive research on the mechanisms of action underlying proT $\alpha$ 's anti-tumor immunological effect has been performed [36], the polypeptide has not yet been introduced in immunotherapeutic protocols for treating cancer patients. There are several reasons for this ambiguity, one of the main being the unclear extracellular molecular mechanism of action of proT $\alpha$. Another is proT $\alpha$ 's length and acidic nature, as it cannot be easily synthesized and/or purified [87]. Most recent reports demonstrate that various areas of the molecule possess diverse activities, for example, amino acids 50-89 of proT $\alpha$ inhibit HIV-1 activity [39], proT $\alpha \Delta 1-29$ and proT $\alpha \Delta 102$ 112 exert anti-necrosis effect [88] (Table 4). We recently reported that the decapeptide spanning residues 100-109 of proT $\alpha$ 's carboxy-terminus ( $\operatorname{proT} \alpha(100-109)$; TKKQK TDEDD) is the actual immunoactive area of the polypeptide and a most potent lymphocyte stimulator [89]. ProT $\alpha(100-109)$ induces PBMC proliferation and cytotoxicity, promotes the maturation of dendritic cells (DC), adopts a $\beta$-sheet conformation, and its effects are sequence-specific and comparable to that of intact proT $\alpha$. In an earlier study, we had shown that a slightly smaller segment (103-109) was also effective in restoring the immune function of PBMC obtained from cancer patients in vitro [90]. As for today, the peptide TKKQKTDEDD is known to be generated in vivo upon caspase-cleavage of proT $\alpha$ during apoptosis [91, 92], and additional mechanisms of its generation and immunoreactivity are currently being investigated in our laboratory. Therefore, besides the scientific interest in elucidating the immunological role of proT $\alpha$ and revealing a link between its two distinct functions, intracellular/proliferative and extracellular/immunomodulatory (Fig. 1), the identification of a smaller proT $\alpha$-related peptide with immunomodulatory, possibly also with anticancer activity, may provide a novel compound that could help improve immune deficiencies associated with cancer.
Table 4 Prothymosin $\alpha$ peptides with recorded activity

n.t. not tested

\begin{tabular}{llll}
\hline $\begin{array}{l}\text { Fragment (amino } \\
\text { acid residues) }\end{array}$ & Nomenclature & Activity & Ref. \\
\hline $\operatorname{ProT} \alpha(1-28)$ & T $\alpha 1$ & $\begin{array}{l}\text { Immunomodulatory; DC activation; anticancer; } \\
\text { antiviral; antifungal; vaccine enhancement }\end{array}$ & {$[17]$} \\
$\operatorname{ProT} \alpha(1-24)$ & Des $(25-28) \mathrm{T} \alpha 1$ & n.t. & {$[19]$} \\
$\operatorname{ProT} \alpha(1-35)$ & T $\alpha 11$ & Antifungal & {$[19]$} \\
$\operatorname{ProT} \alpha(50-89)$ & & Anti-HIV-1 & {$[39]$} \\
$\operatorname{ProT} \alpha(100-109)$ & & Immunomodulatory; DC maturation; anticancer & {$[89]$} \\
$\operatorname{ProT} \alpha(30-109)$ & ProT $\alpha \Delta 1-29$ & Anti-necrotic & {$[88]$} \\
$\operatorname{ProT} \alpha(1-101)$ & ProT $\alpha \Delta 102-112$ & Anti-necrotic & {$[88]$} \\
\hline
\end{tabular}




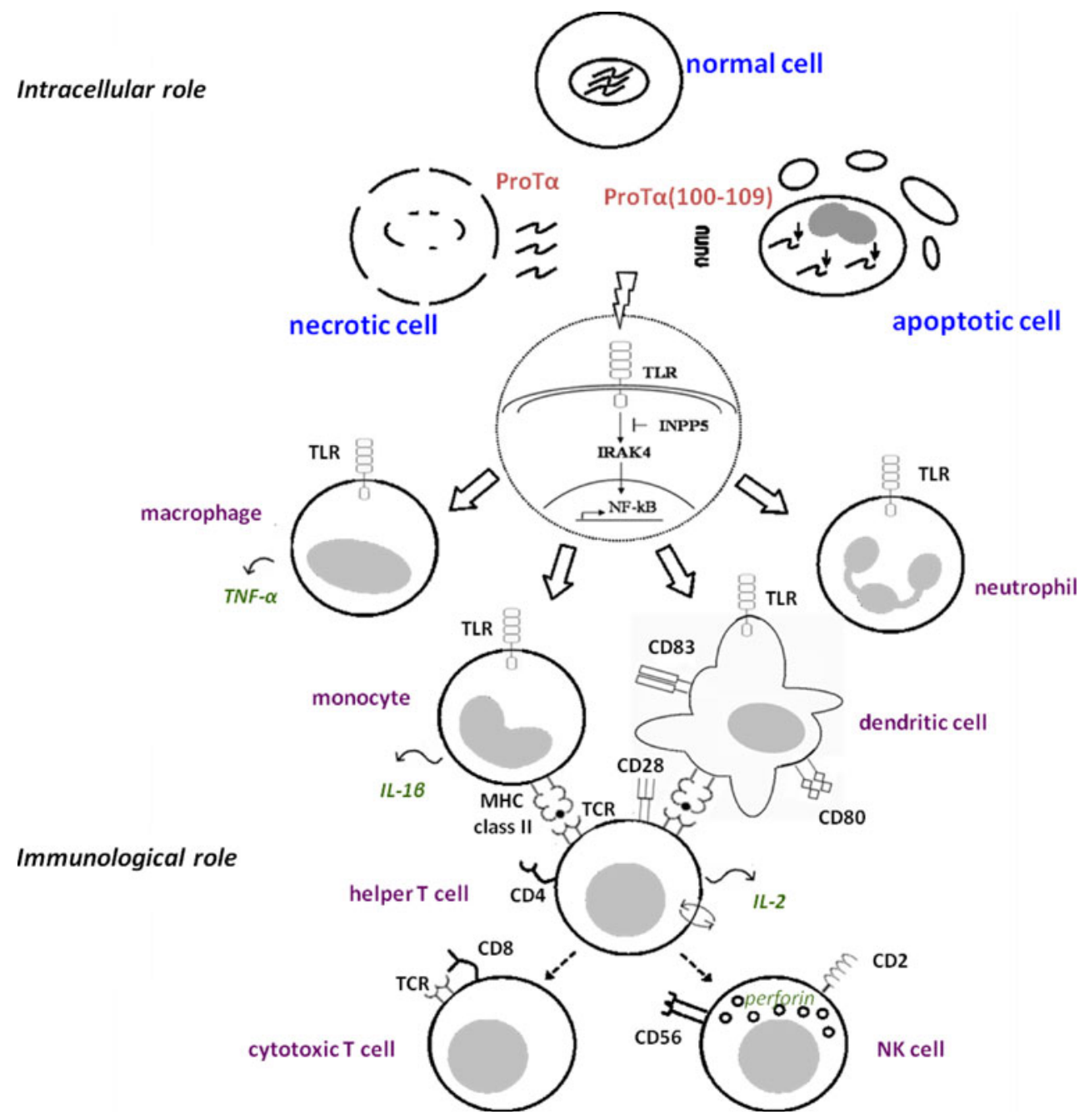

Fig. 1 A proposed scenario explaining how proT $\alpha$ exerts its dual (intra- and extracellular) biologic effect. In a normal cell, proT $\alpha$ is mainly localized in the cell nucleus, where it regulates gene expression and cell proliferation. Under abnormal conditions, cells responding to danger signals die via necrosis or apoptosis. During necrosis, cell components, such as intact proT $\alpha$, are released extracellularly, due to cell membrane disruption. During apoptosis, proT $\alpha$ is relocalized in the cytoplasm, where its carboxy-terminus is cleaved by caspases. ProT $\alpha$ 's truncation generates the immunoactive peptide, $\operatorname{proT} \alpha(100-109)$, which polymerizes into $\beta$-sheet structures and is excreted from the cell. Extracellularly, both proT $\alpha$ and proT $\alpha(100-109)$ activate innate-immunity cells, for example, macrophages, monocytes, DC and neutrophils via TLR-ligation and signaling. Stimulation of monocytes and DC enhances antigen presentation and strengthens their synapsis with $\mathrm{T}$ cells. DC stimulate $\mathrm{T}$ cell proliferation and cytokine production, thus providing a favorable environment for enhancing specific and non-specific cytotoxicity. Consequently, effector cells produce lytic molecules (e.g., perforin) and upregulate adhesion-molecule expression (e.g., CD2). In the presence of specific antigens, CD8+ T cell cytotoxicity is enhanced. secretion of cytokine; $\longleftrightarrow$ stimulation of proliferation
Preclinical studies with $T \alpha 1$ : the first step toward clinical trials

An early sign that $T \alpha 1$ might be active against tumors and of clinical value was first suggested about 25 years ago, when Favalli and coworkers revealed that $\mathrm{T} \alpha 1$-treatment for 4 days, followed by a single injection of IFN- $\alpha / \beta$, restored lymphocyte activity in cyclophosphamide (CY)suppressed tumor-bearing mice [93]. T $\alpha 1$ stimulated the tumor-specific T and NK cell-mediated cytotoxic activity of lymphocytes, whereas mice bearing Lewis lung (3LL) carcinoma administered CY and subsequently treated with
T $\alpha 1+$ IFN- $\alpha / \beta$ [94] or IL-2 [95], showed an increase of tumor-infiltrating lymphoid cells and consequently a dramatic and rapid tumor regression. In the same mouse model, T $\alpha 1$ was shown to synergize with the cytokine cocktail IRX-2 (pooled supernatant of phytohemagglutininstimulated normal donors' PBL), leading to significant improvement in the survival of the animals [96].

$\mathrm{T} \alpha 1$ was further shown to be beneficial in rodents inoculated with other types of tumors (Table 5). When accompanied by low-dose IL- 2 or IFN- $\alpha / \beta$, CY-treated mice challenged with Friend's leukemia cells experienced complete tumor regression and a significant percentage of them 
Table 5 Thymosin $\alpha 1$ as a therapeutic agent for in vivo cancer treatment

\begin{tabular}{|c|c|c|c|}
\hline Cancer/Species & Treatment & Effect & Ref. \\
\hline \multicolumn{4}{|c|}{ Preclinical/animal studies } \\
\hline Colorectal/mouse & $\mathrm{T} \alpha 1+\mathrm{IL}-2+5-\mathrm{FU}$ & $\begin{array}{l}\text { Increase of NK cell activity; increase of CD4+ and CD8+ cells } \\
\text { in the periphery; prevention of extra-hepatic tumor spread; } \\
\text { reduction in liver metastases; increase of survival }\end{array}$ & {$[98,99]$} \\
\hline Leukemia/mouse & $\mathrm{T} \alpha 1+(\mathrm{IL}-2$ or IFN- $\alpha / \beta)+\mathrm{CY}$ & Complete tumor regression; cure & [97] \\
\hline Lung/mouse & $\begin{array}{l}\mathrm{T} \alpha 1+\mathrm{IFN}-\alpha / \beta \\
\mathrm{T} \alpha 1+\mathrm{IL}-2 \\
\mathrm{~T} \alpha 1+\mathrm{IRX}-2\end{array}$ & $\begin{array}{l}\text { Increase of tumor-infiltrating lymphoid cells } \\
\text { Rapid tumor regression } \\
\text { Increase of survival }\end{array}$ & [94-96] \\
\hline Lymphoma/mouse & $\mathrm{T} \alpha 1$ & $\begin{array}{l}\text { TAM activation; increase of TAM-derived IL- } 1, \text { TNF- } \alpha \text {, nitric oxide, } \\
\text { reactive oxygen intermediates; increase of pino/phagocytosis, } \\
\text { antigen presentation and cytotoxicity of PMN }\end{array}$ & {$[100]$} \\
\hline Melanoma/mouse & $\mathrm{T} \alpha 1+\mathrm{IFN}-\alpha / \beta+\mathrm{CY}$ & $\begin{array}{l}\text { Restoration of lymphocytic activity; stimulation of tumor-specific } \\
\text { and NK cell cytotoxicity }\end{array}$ & [93] \\
\hline \multicolumn{4}{|l|}{ Clinical studies } \\
\hline \multirow[t]{4}{*}{ NSCL/human } & $\mathrm{T} \propto 1$ & $\begin{array}{l}\text { Maintenance of normal CD4+ T cell counts; increase of } \\
\text { relapse-free and overall survival }\end{array}$ & {$[101]$} \\
\hline & $\mathrm{T} \alpha 1+\mathrm{IFN}-\alpha-2 \alpha+\mathrm{CDDP}+\mathrm{V} 16$ & $\begin{array}{l}\text { Complete/partial response in some patients; increase } \\
\text { of median survival }\end{array}$ & {$[103]$} \\
\hline & T $\alpha 1+$ IFN- $\alpha+$ ifosfamide & $\begin{array}{l}\text { Maintenance of normal CD4+, CD8+ T cell and NK cell counts; } \\
\text { decrease of hematologic toxicity; increase of average response; } \\
\text { increase of time-to-progression }\end{array}$ & [104] \\
\hline & T $\alpha 1+$ IFN- $\alpha+$ DTIC & Increase of NK cell cytotoxicity; increase of CD4+ T cell counts & [105] \\
\hline \multirow[t]{3}{*}{ Melanoma/human } & T $\alpha 1+$ IL-2 + DTIC & $\begin{array}{l}\text { Complete response/stable disease in some patients; } \\
\text { increase of median survival }\end{array}$ & {$[102]$} \\
\hline & $\mathrm{T} \alpha 1+\mathrm{IFN}-\alpha+\mathrm{DTIC}$ & $\begin{array}{l}\text { Complete/partial response in some patients; } \\
\text { increase of median survival; } \\
\text { increase of median time-to-progression }\end{array}$ & {$[105]$} \\
\hline & $\mathrm{T} \alpha 1+\mathrm{DTIC}$ & $\begin{array}{l}\text { Increase of patients experiencing tumor response; } \\
\text { increase of duration of response; increase of median survival; } \\
\text { increase of progression-free survival }\end{array}$ & [106] \\
\hline Liver/human & $\mathrm{T} \alpha 1+\mathrm{TACE}$ & $\begin{array}{l}\text { Increase of } \mathrm{CD} 3+, \mathrm{CD} 8+, \mathrm{CD} 16 / 56+\text { cell counts; increase of time } \\
\text { to recurrence; increase of median and overall survival; } \\
\text { full protection from bacterial infections }\end{array}$ & [107-109] \\
\hline
\end{tabular}

were even cured [97]. Similarly, in a colorectal cancer model in rats, administration of 5-fluorouracil (5-FU) followed by $\mathrm{T} \alpha 1$ and low-dose IL-2 increased peripheral blood NK cell activity, leading to considerable reduction in liver metastases and prevention of extra-hepatic tumor spreading [98]. When the same research team optimized the aforementioned triple chemo-immunotherapeutic combination, an increase in the number of CD4+ and CD8+ T cells in the periphery was observed, which prevented extrahepatic metastases, and thus considerably increased the average survival time of the animals [99].

To elucidate the mode of action of T $\alpha 1$, Shrivastava and colleagues extensively studied murine macrophages selectively activated by the peptide [100]. When mice bearing spontaneous T cell lymphoma (Dalton's lymphoma (DL)) were treated with $\mathrm{T} \alpha 1$, their tumor-associated macrophages (TAM) were directly responsive to the peptide, were highly activated, produced high levels of IL-1, TNF- $\alpha$, reactive oxygen intermediates, nitric oxide and exhibited increased pinocytosis, phagocytosis, antigen presentation and tumor cytotoxicity. When tested ex vivo, these TAM efficiently differentiated to DC with enhanced antitumor activity. Most importantly, adoptive transfer of T $\alpha 1$-treated peritoneal macrophages in DL-bearing mice delayed tumor growth and prolonged their survival [100]. The outcome of this study demonstrated for the first time that, similarly to proT $\alpha, T \alpha 1$ acts upstream lymphocyte activation, by stimulating macrophages, rendering them capable of directly destroying cancer cells, and by indirectly activating other immune cells via cytokine secretion.

Clinical studies with $\mathrm{T} \alpha 1$

These animal studies indicated that $\mathrm{T} \alpha 1$ could be effective in humans, in principle for immune restoration following chemotherapy, and several trials to evaluate its efficacy 
were licensed. The first was conducted in 1985 by the group of Alan Goldstein [101], where in post-irradiated non-small cell lung (NSCL) cancer patients (42 individuals), administration of $\mathrm{T} \alpha 1\left(900 \mu \mathrm{g} / \mathrm{m}^{2} /\right.$ day $)$ for 14 days showed normalization or maintenance of normal CD4+ T cell percentages and improvement of relapse-free and overall survival. Several years later in 1994 [102], patients with metastatic melanoma (46 in total) were treated with dacarbazine (DTIC), followed by 2 s.c. doses of T $\alpha 1$ ( $2 \mathrm{mg} / \mathrm{dose})$ and IL-2. Complete response was recorded in 2 patients and stable disease in 5, median survival was 11 months, and the toxicity of the regimen was acceptable. Further, a phase II study was conducted in 1995 to evaluate the efficacy of cisplatin (CDDP) and etoposide (VP-16) combined with T $\alpha 1$ $(1 \mathrm{mg} / \mathrm{day} ; 11$ doses s.c.) and low-dose IFN- $\alpha-2 \alpha$ for the treatment of 56 patients with advanced NSCL cancer [103]. Two patients experienced complete and 22 a partial response to treatment, which, as a whole, was well tolerated; median survival was 12.6 months. Although the chemotherapeutic drugs depressed NK cell activity and lymphocyte number, their adverse effects were less prominent in patients also receiving $\mathrm{T} \alpha 1+\mathrm{IFN}-\alpha-2 \alpha$. A subsequent phase II randomized trial was conducted by Salvati and colleagues [104]. Twenty-two patients with advanced NSCL cancer were randomized to receive only ifosfamide (chemotherapy) or ifosfamide followed by $\mathrm{T} \alpha 1$ (same dose as in [103]) + low-dose IFN- $\alpha$ (chemo-immunotherapy). The latter enhanced the average response rate to $33 \%$ compared to $10 \%$ of chemotherapy alone. Although these percentages were not significant, the difference in timeto-progression was statistically significant, and patients receiving chemo-immunotherapy showed reduced hematologic toxicity and no decrease in CD4+, CD8+ T and NK cell counts [104]. Following the initial study of Lopez and colleagues [102], the evaluation of the effect of $T \alpha 1$ was extended in a phase II open trial for advanced metastatic melanoma [105]. Out of 20 stage III/IV patients treated with DTIC + T $\alpha 1(1 \mathrm{mg} /$ day; s.c.; 8 doses at chemotherapy intervals for 3-9 cycles) + low-dose IFN- $\alpha, 5$ patients experienced complete and 5 more a partial response. Median survival and median time-to-progression were 11.5 and 5.5 months, respectively, and no toxicity was recorded. As in NSCL cancer, patients treated with the triple combination showed improved NK cell activity and higher CD4+ T cell counts compared to those receiving only DTIC. Taken altogether, melanoma and NSCL cancer patients who were administered $T \alpha 1$ did not benefit dramatically in terms of complete response or survival time, but incorporation of the peptide to standard chemotherapy regimes improved the functionality and counts of some lymphocyte subsets (NK cell cytotoxicity; $\mathrm{CD} 4+/ \mathrm{CD} 8+\mathrm{T}$ cell ratio).

Most recently, the largest, thus far, multicenter open randomized trial in metastatic melanoma patients evaluating
T $\propto 1$ administration was completed. Maio and coworkers [106] recruited 488 stage IV patients from 64 centers and treated them with DTIC + IFN- $\alpha$, DTIC + T $\alpha 1$ or DTIC + IFN- $\alpha+$ T $\alpha 1$ (1.6-6.4 mg; s.c.; 8 doses at chemotherapy intervals for 6 cycles). After a 24-month follow-up, the findings of this study were that adding $\mathrm{T} \alpha 1$ to chemotherapy (a) increased the number of patients experiencing tumor response (11.2 vs $4.1 \%$ ); (b) increased their median overall survival by 2.8 months ( 9.4 vs 6.6 ); (c) improved the duration of response from 1.9 to 23.2 months; (d) increased 6-month progression-free survival by $12 \%$ (21.1 vs $9.1 \%$ ); and (e) was safe and non-toxic. In agreement with the initial study of Schulof et al. [101], T $\alpha 1$ could potentiate the efficacy of DTIC with or without the concomitant addition of IFN- $\alpha$.

Three more trials, set on a different basis, evaluated the therapeutic potential of $T \alpha 1$ in patients post-hepatectomy or with unresectable hepatocellular carcinoma treated with transarterial chemoembolization (TACE). In the first [107], $\mathrm{T} \alpha 1\left(900 \mu \mathrm{g} / \mathrm{m}^{2}\right.$; s.c.; twice weekly for 6 months) prolonged patients' survival and increased significantly the percentages of $\mathrm{CD} 3+, \mathrm{CD} 8+, \mathrm{CD} 16 / 56+$ cells after 1 month of treatment. In the second [108], T $\alpha 1$ increased patients' time to tumor recurrence by 3 months and median survival by 2 months. Finally, in the most recent phase II randomized trial of Gish and colleagues [109], the same dose of peptide, but administered to the patients almost daily (1.6 mg; s.c.; 5-times weekly for 6 months), conferred full protection from bacterial infections and increased overall survival for over 13 months compared to T $\alpha 1$-untreated patients.

As with any novel agent introduced in the clinic, an important issue that should be discussed at this point with respect to the use of $T \alpha 1$ in humans is toxicity and safety. In the most recent methodical review of Wolf and colleagues [110], these parameters were extensively analyzed among other thymic peptides also for $\mathrm{T} \alpha 1$. According to the aforementioned clinical studies, $\mathrm{T} \alpha 1$ doses up to $6.4 \mathrm{mg}$ were safe, did not induce toxicity and lacked severe side effects. When given in combination with chemotherapy, no adjunctive toxicity or interference between chemo- and immunotherapy was recorded; on the contrary in many cases, $\mathrm{T} \alpha 1$ allowed a general reduction in intrinsic toxicity of chemotherapeutic drugs. Immunological monitoring of some of the recruited patients showed a cyclic variation in immune responses, with a dramatic decline after chemotherapy and a boosting after $T \alpha 1$ treatment, which occurred repeatedly during each cycle of therapy. Unfortunately, as this, unique for the moment, overall evaluation concludes, only weak evidence supports the clinical effectiveness of $\mathrm{T} \alpha 1$ on the management of cancer, although some patients undergoing chemotherapy might benefit via $\mathrm{T} \alpha 1$-induced reduction in the risk of infectious complications. 
Discussing our current view of proT $\alpha$ and its potential clinical implications

All the aforementioned in vitro and in vivo studies with proT $\alpha$, as well as the experience gained from the clinical trials conducted for $T \alpha 1$, have brought to light some interesting observations. Firstly, the levels of proT $\alpha$ in cancer tissues, maybe also in biologic fluids such as urine, should be appropriately validated in order for the polypeptide to be used as a potential biomarker for cancer prognosis and progression. In the case of a heterogeneous disease like cancer, such a study will require samples from a cohort of many cancer patients, classified on the basis of their tumors' histological characteristics, stage of the disease, treatment approach and long-term follow-up, in conjunction with clinical responses and the values of already established biomarkers. Secondly, due to its elevated expression in cancer cells, targeting intracellular proT $\alpha$, consequently inhibiting its activity, is predicted to cause the inability of cancer cells to proliferate and the induction of cancer cell apoptosis. The eventual development and in vivo testing of $\operatorname{proT} \alpha$ specific inhibitors could provide a future option for anticancer treatment. Thirdly, administration of proT $\alpha$ can provide, via a variety of mechanisms, some as yet unknown, the appropriate environment (i.e., a stimulating cytokine milieu) that enhances the efficacy of tumor-specific and non-specific effector cells, as already shown in vitro and in animals in vivo. As current approaches for cancer patient treatment and management encourage adjuvant therapy, proT $\alpha$ could be an excellent candidate that could act cooperatively with other cancer therapies, for example, chemotherapy and/or irradiation. Finally, from experience to date, administration of relatively high concentrations of $\operatorname{proT} \alpha$ in animals and of $T \alpha 1$ in animals and humans lacks toxicity and severe adverse effects.

The apparent question that arises is how can the same molecule, proT $\alpha$, adopt different properties and carry out discrete and different functions depending on whether it is localized inside or outside the cell. This paradox is not unique to proT $\alpha$. It has already been described for a series of proteins, prominent examples being heat-shock protein (HSP) 90 and high mobility group protein B1 (HMGB1) [111]. Both HSP90 and HMGB1 have well-characterized intracellular functions (as a molecular chaperone and a regulator of transcription, respectively), but when excreted, by non-classical ER-Golgi-independent secretory pathways, have documented extracellular roles, related to immunomodulation (as proinflammatory cytokine-like mediators) [112, 113]. HSP90 and HMGB1 interact with TLR, possibly also with other pattern recognition receptors (PRR) and sensitize innate immune cells (e.g., DC), thus promoting adaptive immune responses. These endogenous molecules are now classified in the diverse group of factors termed "alarmins," to which more molecules are constantly being added. In fact, thymosins are now considered as putative alarmins, as they share several common characteristics and modes of action with HSP and HMGB [40]. In the case of proT $\alpha$, these shared properties were further complemented by the recent finding that in human macrophages, proT $\alpha$ signals via ligating TLR4, the most promiscuous of the TLR, binding also HSP90 and HMBG1 [39]. This data confirmed our previous observation that proT $\alpha$-stimulated human monocytes upregulated the expression of IRAK4 [85].

From a practical viewpoint and in relevance to anticancer treatment, HSP90 and HMGB1 have recently been proposed as target molecules for developing novel anticancer strategies, and clinical trials have already been scheduled $[114,115]$. Thus, our suggestion that proT $\alpha$ per se can be targeted to inhibit cancer cell development is not promisorial and could provide a novel means of anticancer treatment. Furthermore, taking as paradigms HSP90 and HMGB1, proT $\alpha$ could act as an adjuvant stimulating immune responses to specific peptides or tumor antigens, without causing severe adverse effects. Unpublished data from our laboratory show that in the presence of specific HER-2/neu epitopes, DC matured with proT $\alpha$ or its immunoactive decapeptide, $\operatorname{proT} \alpha(100-109)$ [89], not only exhibit the appropriate phenotype, but are functionally competent to induce HER-2/neu-specific CD4+ and CD8+ $\mathrm{T}$ cells responses in vitro (Ioannou et al. manuscript in preparation). It is of interest to note that a smaller peptide deriving from HMGB1 has been reported to possess similar immune functionalities as the parental molecule [116].

The use of TLR ligands as adjuvants is a matter of intense investigation, as they are critical compounds for the success of antitumor vaccination. Notable examples are CpG oligodeoxynucleotides signaling through TLR9, single- or double (poly-I:C)-stranded RNA, ligating TLR7/8 and 3, imiquimod, a TLR7 agonist and monophosphoryl lipid A (MPLA), a TLR4 agonist, the latter being the only adjuvant approved for human use since alum [117]. The recent phase I/II trial in prostate cancer patients vaccinated with synthetic peptides combined with imiquimod proved that TLR7 coactivation was beneficial for the induction of strong antitumor immunity and the generation of clinical responses [118]. Therefore, at this stage, it would be quite challenging to propose proT $\alpha$ or its $\mathrm{C}$-terminal fragment as new adjuvant candidates to enhance the efficacy of cancer vaccines.

\section{Conclusion}

Considering the distinct properties of proT $\alpha$, the next step should be research aimed primarily at independently 
evaluating the potency of proT $\alpha$ 's combination with chemo-, radiotherapy and/or antitumor vaccination and maybe, its potential use in predicting cancer outcome. Using the appropriate control groups, randomized trials on cancer patients may offer the opportunity making advances in cancer treatment in the near future.

Accrued data point to the design of clinical studies integrating either the full length polypeptide or, preferably, its immunoactive fragment(s) (Table 4), as adjuvants to currently applied vaccination regimes for treating cancer patients. The lessons learned so far suggest that in order to verify the immunostimulating efficacy of proT $\alpha$, administration of the polypeptide, or of its immunoactive fragment(s), at chemotherapy intervals, for definitely more than one chemotherapy cycle and possibly for a prolonged period of treatment, could be a therapeutic choice.

At this point, and albeit intensive research followed by published studies/trials on the ways of using this polypeptide in humans needs to be supplied, it is worth mentioning that proT $\alpha$ is available in the form of a "drug" [119], and indications, dosage and administration instructions for its use in patients are provided in the above mentioned website.

After almost three decades of research, the initial notion that the thymic peptide proT $\alpha$ might be useful for treating human diseases remains promising. In the case of cancer where immune system integrity is of the utmost importance, the use of proT $\alpha$, most likely in combination with other immune modulators, still appears to offer potential.

\begin{abstract}
Acknowledgments We thank Dr. Margarita Skopeliti for compiling the figure and critically reading the manuscript. Co-financed by: the European Union (European Social Fund-ESF) and Greek national funds through the Operational Program "Education and Lifelong Learning" of the National Strategic Reference Framework (NSRF) Research Funding Program: Heracleitus II. Investing in knowledge society through the European Social Fund (to K.I.); the Hellenic State Scholarship Foundation (IKY) and the Deutscher Akademischer Austauschdienst (DAAD), IKYDA 61/2003 and IKYDA 165/2010; the European Union FP7 Capacities grant REGPOT-CT-2011-284460, INsPiRE; NATO SfP Project 982838; “GERONTOSHIELD” (BMBF Project 0315890F).
\end{abstract}

Conflict of interest The authors declare that they have no conflict of interest.

\section{References}

1. Miller JF (1961) Immunological function of the thymus. Lancet 2:748-749

2. Good RA, Dalmasso AP, Martinez C, Archer OK, Pierce JC, Papermaster BW (1962) The role of the thymus in development of immunologic capacity in rabbits and mice. J Exp Med 116:773-796

3. Aisenberg AC, Wilkes B (1965) Partial immunological restoration of neonatally thymectomized rats with thymus-containing diffusion chambers. Nature 205:716-717
4. Berthiaume F, Aparicio CL, Eungdamrong J, Yarmush ML (1999) Age- and disease-related decline in immune function: an opportunity for "thymus-boosting" therapies. Tissue Eng 5:499-514

5. Schulof RS (1985) Thymic peptide hormones: basic properties and clinical applications in cancer. Crit Rev Oncol Hematol 3:309-376

6. Klein JJ, Goldstein AL, White A (1965) Enhancement of in vivo incorporation of labeled precursors into DNA and total protein of mouse lymph nodes after administration of thymic extracts. Proc Natl Acad Sci USA 53:812-817

7. Goldstein AL, Slater FD, White A (1966) Preparation, assay, and partial purification of a thymic lymphocytopoietic factor (thymosin). Proc Natl Acad Sci USA 56:1010-1017

8. Hooper JA, McDaniel MC, Thurman GB, Cohen GH, Schulof RS, Goldstein AL (1975) Purification and properties of bovine thymosin. Ann N Y Acad Sci 249:125-144

9. Spangelo BL, Hall NR, Goldstein AL (1987) Biology and chemistry of thymosin peptides. Modulators of immunity and neuroendocrine circuits. Ann N Y Acad Sci 496:196-204

10. Wara DW, Ammann AJ (1975) Activation of T-cell rosettes in immunodeficient patients by thymosin. Ann N Y Acad Sci 249:308-315

11. Dauphinee MJ, Talal N, Goldstein AL, White A (1974) Thymosin corrects the abnormal DNA synthetic response of NZB mouse thymocytes. Proc Natl Acad Sci USA 71:2637-2641

12. Spangelo BL, Farrimond DD, Pompilius M, Bowman KL (2000) Interleukin- $1 \beta$ and thymic peptide regulation of pituitary and glial cell cytokine expression and cellular proliferation. Ann N Y Acad Sci 917:597-607

13. Ho AD, Ma DD, Price G, Hunstein W, Hoffbrand AV (1983) Biochemical and immunological differentiation of human thymocytes induced by thymic hormones. Immunology 50:471-476

14. Spangelo BL, Roach JD, Hadi F, Damavandy AA, Plieskatt J, Badamchian M (2007) Thymosin fraction-5 possesses antiproliferative properties in HL-60 human promyelocytic leukemia cells: characterization of an active peptide. Ann N Y Acad Sci 1112:305-316

15. Khaw BA, Rule AH (1973) Immunotherapy of the Dunning leukemia with thymic extracts. Br J Cancer 28:288-292

16. Petro TM, Watson RR (1982) Resistance to L1210 mouse leukemia cells in moderately protein-malnourished BALB/c mice treated in vivo with thymosin fraction V. Cancer Res 42:21392145

17. Goldstein AL (2007) History of the discovery of the thymosins. Ann N Y Acad Sci 1112:1-13

18. Haritos AA, Goodall GJ, Horecker BL (1984) Prothymosin alpha: isolation and properties of the major immunoreactive form of thymosin alpha 1 in rat thymus. Proc Natl Acad Sci USA 81:1008-1011

19. Hannappel E, Huff T (2003) The thymosins. Prothymosin alpha, parathymosin, and beta-thymosins: structure and function. Vitam Horm 66:257-296

20. Haritos AA, Tsolas O, Horecker BL (1984) Distribution of prothymosin alpha in rat tissues. Proc Natl Acad Sci USA 81:13911393

21. Eschenfeldt WH, Berger SL (1986) The human prothymosin alpha gene is polymorphic and induced upon growth stimulation: evidence using a cloned cDNA. Proc Natl Acad Sci USA 83:9403-9407

22. Szabo P, Ehleiter D, Whittington E, Weksler ME (1992) Prothymosin alpha expression occurs during G1 in proliferating $B$ or T lymphocytes. Biochem Biophys Res Commun 185:953959

23. Wu CL, Shiau AL, Lin CS (1997) Prothymosin alpha promotes cell proliferation in NIH3T3 cells. Life Sci 61:2091-2101 
24. Sburlati AR, Manrow RE, Berger SL (1991) Prothymosin alpha antisense oligomers inhibit myeloma cell division. Proc Natl Acad Sci USA 88:253-257

25. Jiang X, Kim HE, Shu H, Zhao Y, Zhang H, Kofron J, Donnelly J, Burns D, Ng SC, Rosenberg S, Wang X (2003) Distinctive roles of PHAP proteins and prothymosin-alpha in a death regulatory pathway. Science 299:223-226

26. Karetsou Z, Kretsovali A, Murphy C, Tsolas O, Papamarcaki T (2002) Prothymosin alpha interacts with the CREB-binding protein and potentiates transcription. EMBO Rep 3:361-366

27. Gomez-Marquez J, Rodriguez P (1998) Prothymosin alpha is a chromatin-remodelling protein in mammalian cells. Biochem $\mathrm{J}$ 333:1-3

28. Eilers M, Schirm S, Bishop JM (1991) The MYC protein activates transcription of the alpha-prothymosin gene. EMBO J 10:133-141

29. Niture SK, Kaspar JW, Shen J, Jaiswal AK (2010) Nrf2 signaling and cell survival. Toxicol Appl Pharmacol 244:37-42

30. Pan LX, Haritos AA, Wideman J, Komiyama T, Chang M, Stein S, Salvin SB, Horecker BL (1986) Human prothymosin alpha: amino acid sequence and immunologic properties. Arch Biochem Biophys 250:197-201

31. Baxevanis CN, Frillingos S, Seferiadis K, Reclos GJ, Arsenis P, Katsiyiannis A, Anastasopoulos E, Tsolas O, Papamichail M (1990) Enhancement of human T lymphocyte function by prothymosin alpha: increased production of interleukin-2 and expression of interleukin-2 receptors in normal human peripheral blood T lymphocytes. Immunopharmacol Immunotoxicol 12:595-617

32. Cordero OJ, Sarandeses CS, López JL, Cancio E, Regueiro BJ, Nogueira M (1991) Prothymosin alpha enhances interleukin 2 receptor expression in normal human T-lymphocytes. Int J Immunopharmacol 13:1059-1065

33. Baxevanis CN, Thanos D, Reclos GJ, Anastasopoulos E, Tsokos GC, Papamatheakis J, Papamichail M (1992) Prothymosin alpha enhances human and murine MHC class II surface antigen expression and messenger RNA accumulation. J Immunol 148:1979-1984

34. Cordero OJ, Sarandeses CS, López JL, Nogueira M (1992) Prothymosin alpha enhances human natural killer cell cytotoxicity: role in mediating signals for NK activity. Lymphokine Cytokine Res 11:277-285

35. López-Rodríguez JL, Cordero OJ, Sarandeses C, Viñuela J, Nogueira M (1994) Interleukin-2 killer cells: in vitro evaluation of combination with prothymosin alpha. Lymphokine Cytokine Res 13:175-182

36. Piñeiro A, Cordero OJ, Nogueira M (2000) Fifteen years of prothymosin alpha: contradictory past and new horizons. Peptides 21:1433-1446

37. Piñeiro A, Begoña Bugia M, Pilar Arias M, Cordero OJ, Nogueira M (2001) Identification of receptors for prothymosin alpha on human lymphocytes. Biol Chem 382:1473-1482

38. Salgado FJ, Piñeiro A, Canda-Sánchez A, Lojo J, Nogueira M (2005) Prothymosin alpha-receptor associates with lipid rafts in PHA-stimulated lymphocytes. Mol Membr Biol 22:163-176

39. Mosoian A, Teixeira A, Burns CS, Sander LE, Gusella GL, He C, Blander JM, Klotman P, Klotman ME (2010) Prothymosin-alpha inhibits HIV-1 via Toll-like receptor 4-mediated type I interferon induction. Proc Natl Acad Sci USA 107:10178-10183

40. Bianchi ME (2007) DAMPs, PAMPs and alarmins: all we need to know about danger. J Leukoc Biol 81:1-5

41. Mosoian A (2011) Intracellular and extracellular cytokine-like functions of prothymosin $\alpha$ : implications for the development of immunotherapies. Future Med Chem 3:1199-1208

42. Bustelo XR, Otero A, Gomez-Marquez J, Freire M (1991) Expression of the rat prothymosin alpha gene during T-lymphocyte proliferation and liver regeneration. J Biol Chem 266:1443-1447
43. Alvarez CV, Zalvide JB, Cancio E, Dieguez C, Regueiro BJ, Vega FV, Dominguez F (1993) Regulation of prothymosin alpha mRNA levels in rat pituitary tumor cells. Neuroendocrinology 57:1048-1056

44. Wu CG, Boers W, Reitsma PR, van Deventer SJ, Chamuleau RA (1997) Overexpression of prothymosin alpha, concomitant with c-myc, during rat hepatic carcinogenesis. Biochem Biophys Res Commun 232:817-821

45. Mori M, Barnard GF, Staniunas RJ, Jessup JM, Steele GD Jr, Chen LB (1993) Prothymosin-alpha mRNA expression correlates with that of c-myc in human colon cancer. Oncogene 8:2821-2826

46. Wu CG, Habib NA, Mitry RR, Reitsma PH, van Deventer SJ, Chamuleau RA (1997) Overexpression of hepatic prothymosin alpha, a novel marker for hepatocellular carcinoma. Br J Cancer 76:1199-1204

47. Sasaki H, Sato Y, Kondo S, Fukai I, Kiriyama M, Yamakawa Y, Fujii Y (2001) Expression of the prothymosin alpha mRNA correlated with that of $\mathrm{N}$-myc in neuroblastoma. Cancer Lett 168:191-195

48. Sasaki H, Nonaka M, Fujii Y, Yamakawa Y, Fukai I, Kiriyama M, Sasaki M (2001) Expression of the prothymosin-alpha gene as a prognostic factor in lung cancer. Surg Today 31:936-938

49. Carey KA, Segal D, Klein R, Sanigorski A, Walder K, Collier GR, Cameron-Smith D (2006) Identification of novel genes expressed during rhabdomyosarcoma differentiation using cDNA microarrays. Pathol Int 56:246-255

50. Letsas KP, Vartholomatos G, Tsepi C, Tsatsoulis A, FrangouLazaridis M (2007) Fine-needle aspiration biopsy-RT-PCR expression analysis of prothymosin alpha and parathymosin in thyroid: novel proliferation markers? Neoplasma 54:57-62

51. Ojima E, Inoue Y, Miki C, Mori M, Kusunoki M (2007) Effectiveness of gene expression profiling for response prediction of rectal cancer to preoperative radiotherapy. J Gastroenterol 42:730-736

52. Tsitsiloni OE, Stiakakis J, Koutselinis A, Gogas J, Markopoulos C, Yialouris P, Bekris S, Panoussopoulos D, Kiortsis V, Voelter W et al (1993) Expression of alpha-thymosins in human tissues in normal and abnormal growth. Proc Natl Acad Sci USA 90:9504-9507

53. Dominguez F, Magdalena C, Cancio E, Roson E, Paredes J, Loidi L, Zalvide J, Fraga M, Forteza J, Regueiro BJ et al (1993) Tissue concentrations of prothymosin alpha: a novel proliferation index of primary breast cancer. Eur J Cancer 29A:893-897

54. Tsitsilonis OE, Bekris E, Voutsas IF, Baxevanis CN, Markopoulos C, Papadopoulou SA, Kontzoglou K, Stoeva S, Gogas J, Voelter W, Papamichail M (1998) The prognostic value of alpha-thymosins in breast cancer. Anticancer Res 18:15011508

55. Magdalena C, Dominguez F, Loidi L, Puente JL (2000) Tumour prothymosin alpha content, a potential prognostic marker for primary breast cancer. Br J Cancer 82:584-590

56. Suzuki S, Takahashi S, Takahashi S, Takeshita K, Hikosaka A, Wakita T, Nishiyama N, Fujita T, Okamura T, Shirai T (2006) Expression of prothymosin alpha is correlated with development and progression in human prostate cancers. Prostate 66:463-469

57. Klimentzou P, Drougou A, Fehrenbacher B, Schaller M, Voelter W, Barbatis C, Paravatou-Petsotas M, Livaniou E (2008) Immunocytological and preliminary immunohistochemical studies of prothymosin alpha, a human cancer-associated polypeptide, with a well-characterized polyclonal antibody. J Histochem Cytochem 56:1023-1031

58. Tsai YS, Jou YC, Lee GF, Chen YC, Shiau AL, Tsai HT, Wu CL, Tzai TS (2009) Aberrant prothymosin-alpha expression in human bladder cancer. Urology 73:188-192 
59. Jou YC, Tung CL, Tsai YS, Shen CH, Syue-Yi C, Shiau AL, Tsai HT, Wu CL, Tzai TS (2009) Prognostic relevance of prothymosinalpha expression in human upper urinary tract transitional cell carcinoma. Urology 74:951-957

60. Fraga M, García-Caballero T, Domínguez F, Pérez-Becerra E, Beiras A, Forteza J (1993) Immunohistochemical location of prothymosin alpha in regenerating human hepatocytes and hepatocellular carcinomas. Virchows Arch A Pathol Anat Histopathol 423:449-452

61. Pawlikowski M, Winczyk K (2009) Immunohistochemical detection of prothymosin alpha in pituitary adenomas-a new marker of tumor recurrence? Folia Histochem Cytobiol 47:559562

62. Tripathi SC, Matta A, Kaur J, Grigull J, Chauhan SS, Thakar A, Shukla NK, Duggal R, Choudhary AR, Dattagupta S, Sharma MC, Ralhan R, Siu KW (2011) Overexpression of prothymosin alpha predicts poor disease outcome in head and neck cancer. PLoS One 6:e19213

63. Leys CM, Nomura S, LaFleur BJ, Ferrone S, Kaminishi M, Montgomery E, Goldenring JR (2007) Expression and prognostic significance of prothymosin-alpha and ERp57 in human gastric cancer. Surgery 141:41-50

64. Panneerselvam C, Haritos AA, Caldarella J, Horecker BL (1987) Prothymosin alpha in human blood. Proc Natl Acad Sci USA 84:4465-4469

65. Costopoulou D, Leondiadis L, Czarnecki J, Ferderigos N, Ithakissios DS, Livaniou E, Evangelatos GP (1998) Direct ELISA method for the specific determination of prothymosin alpha in human specimens. J Immunoassay 19:295-316

66. Kashat L, So AK, Masui O, Wang XS, Cao J, Meng X, Macmillan C, Ailles LE, Siu KW, Ralhan R, Walfish PG (2010) Secretome-based identification and characterization of potential biomarkers in thyroid cancer. J Proteome Res 9:5757-5769

67. Tzai TS, Tsai YS, Shiau AL, Wu CL, Shieh GS, Tsai HT (2006) Urine prothymosin-alpha as novel tumor marker for detection and follow-up of bladder cancer. Urology 67:294-299

68. Hersh EM, Mansell PW, Reuben JM, Rios A, Newell GR, Goldstein AL, Lynch K (1983) Leukocyte subset analysis and related immunological findings in acquired immunodeficiency disease syndrome (AIDS) and malignancies. Diagn Immunol 1:168-173

69. Sasaki H, Fujii Y, Masaoka A, Yamakawa Y, Fukai I, Kiriyama M, Saito Y, Matsui H (1997) Elevated plasma thymosin-alpha1 levels in lung cancer patients. Eur J Cardiothorac Surg 12:885891

70. Mitani M, Kuwabara Y, Kawamura H, Sato A, Hattori K, Fujii Y (2000) Significance of plasma thymosin alpha 1 measurements in gastric cancer patients. World J Surg 24:455-458

71. Billich A (2002) Thymosin alpha1. SciClone Pharmaceuticals. Curr Opin Investig Drugs 3:698-707

72. Papanastasiou M, Baxevanis CN, Papamichail M (1992) Promotion of murine antitumor activity by prothymosin alpha treatment: I. Induction of tumoricidal peritoneal cells producing high levels of tumour necrosis factor alpha. Cancer Immunol Immunother 35:145-150

73. Baxevanis CN, Gritzapis AD, Dedoussis GV, Papadopoulos NG, Tsolas O, Papamichail M (1994) Induction of lymphokine-activated killer activity in mice by prothymosin alpha. Cancer Immunol Immunother 38:281-286

74. Baxevanis CN, Gritzapis AD, Spanakos G, Tsitsilonis OE, Papamichail M (1995) Induction of tumor-specific T lymphocyte responses in vivo by prothymosin alpha. Cancer Immunol Immunother 40:410-418

75. Baxevanis CN, Reclos GJ, Papamichail M (1993) Prothymosin alpha restores depressed allogeneic cell-mediated lympholysis and natural-killer-cell activity in patients with cancer. Int J Cancer 53:264-268
76. Garbin F, Eckert K, Büttner P, Garbe C, Maurer HR (1994) Prothymosin alpha augments deficient antitumor activity of monocytes from melanoma patients in vitro. Anticancer Res $14: 2405-2411$

77. Eckert K, Garbin F, Maurer HR, Büttner P, Garbe C, Czarnecki J (1995) Prothymosin alpha 1 modulates lymphokine-activated killer cell activity and IL-2 production by peripheral blood lymphocytes from melanoma patients in vitro. Int J Immunopharmacol 17:555-561

78. Eckert K, Grünberg E, Immenschuh P, Garbin F, Kreuser ED, Maurer HR (1997) Interleukin-2-activated killer cell activity in colorectal tumor patients: evaluation of in vitro effects by prothymosin alpha1. J Cancer Res Clin Oncol 123:420-428

79. Garbin F, Eckert K, Immenschuh P, Kreuser ED, Maurer HR (1997) Prothymosin alpha 1 effects, in vitro, on the antitumor activity and cytokine production of blood monocytes from colorectal tumor patients. Int J Immunopharmacol 19:323-332

80. Eckert K, Grünberg E, Garbin F, Maurer HR (1997) Preclinical studies with prothymosin alpha1 on mononuclear cells from tumor patients. Int J Immunopharmacol 19:493-500

81. Baxevanis CN, Spanakos G, Voutsas IF, Gritzapis AD, Tsitsilonis OE, Mamalaki A, Papamichail M (1999) Increased generation of autologous tumor-reactive lymphocytes by anti-CD3 monoclonal antibody and prothymosin alpha. Cancer Immunol Immunother 48:71-84

82. López-Rodríguez JL, Cordero OJ, Sarandeses C, Viñuela J, Nogueira M (1994) Interleukin-2 killer cells: in vitro evaluation of combination with prothymosin alpha. Lymphokine Cytokine Res 13:175-182

83. Cordero OJ, Sarandeses C, López-Rodríguez JL, Nogueira M (1995) The presence and cytotoxicity of CD16+ CD2- subset from PBL and NK cells in long-term IL-2 cultures enhanced by Prothymosin-alpha. Immunopharmacology 29:215-223

84. Voutsas IF, Baxevanis CN, Gritzapis AD, Missitzis I, Stathopoulos GP, Archodakis G, Banis C, Voelter W, Papamichail M (2000) Synergy between interleukin-2 and prothymosin alpha for the increased generation of cytotoxic $\mathrm{T}$ lymphocytes against autologous human carcinomas. Cancer Immunol Immunother 49:449-458

85. Skopeliti M, Kratzer U, Altenberend F, Panayotou G, Kalbacher H, Stevanovic S, Voelter W, Tsitsilonis OE (2007) Proteomic exploitation on prothymosin alpha-induced mononuclear cell activation. Proteomics 7:1814-1824

86. Heidecke H, Eckert K, Schulze-Forster K, Maurer HR (1997) Prothymosin alpha 1 effects in vitro on chemotaxis, cytotoxicity and oxidative response of neutrophils from melanoma, colorectal and breast tumor patients. Int J Immunopharmacol 19:413-420

87. Wilson CL, Monteith WB, Danell AS, Burns CS (2006) Purification and characterization of the central segment of prothymosinalpha: methodology for handling highly acidic peptides. J Pept Sci 12:721-725

88. Cordero OJ (2011) Data on the interaction between prothymosin $\alpha$ and TLR4 may help to the design of new antiviral compounds. J Acquir Immune Defic Syndr 56:e110-e111

89. Skopeliti M, Iconomidou VA, Derhovanessian E, Pawelec G, Voelter W, Kalbacher H, Hamodrakas SJ, Tsitsilonis OE (2009) Prothymosin alpha immunoactive carboxyl-terminal peptide TKKQKTDEDD stimulates lymphocyte reactions, induces dendritic cell maturation and adopts a beta-sheet conformation in a sequence-specific manner. Mol Immunol 46:784-792

90. Skopeliti M, Voutsas IF, Klimentzou P, Tsiatas ML, Beck A, Bamias A, Moraki M, Livaniou E, Neagu M, Voelter W, Tsitsilonis OE (2006) The immunologically active site of prothymosin alpha is located at the carboxy-terminus of the polypeptide. Evaluation of its in vitro effects in cancer patients. Cancer Immunol Immunother 55:1247-1257 
91. Enkemann SA, Wang RH, Trumbore MW, Berger SL (2000) Functional discontinuities in Prothymosin $\alpha$ caused by caspase cleavage in apoptotic cells. J Cell Physiol 182:256-268

92. Evstafieva AG, Belov GA, Rubtsov YP, Kalkum M, Joseph B, Chichkova NV, Sukhacheva EA, Bogdanov AA, Pettersson RF, Agol VI, Vartapetian AB (2003) Apoptosis-related fragmentation, translocation, and properties of human prothymosin alpha. Exp Cell Res 284:211-223

93. Favalli C, Mastino A, Jezzi T, Grelli S, Goldstein AL, Garaci E (1989) Synergistic effect of thymosin alpha 1 and alpha betainterferon on NK activity in tumor-bearing mice. Int J Immunopharmacol 11:443-450

94. Garaci E, Mastino A, Pica F, Favalli C (1990) Combination treatment using thymosin alpha 1 and interferon after cyclophosphamide is able to cure Lewis lung carcinoma in mice. Cancer Immunol Immunother 32:154-160

95. Mastino A, Favalli C, Grelli S, Rasi G, Pica F, Goldstein AL, Garaci E (1992) Combination therapy with thymosin alpha 1 potentiates the anti-tumor activity of interleukin- 2 with cyclophosphamide in the treatment of the Lewis lung carcinoma in mice. Int J Cancer 50:493-499

96. Naylor PH, Quadrini K, Garaci E, Rasi G, Hadden JW (2007) Immunopharmacology of thymosin alpha1 and cytokine synergy. Ann N Y Acad Sci 1112:235-244

97. Garaci E, Pica F, Mastino A, Palamara AT, Belardelli F, Favalli C (1993) Antitumor effect of thymosin alpha 1/interleukin-2 or thymosin alpha $1 /$ interferon alpha, beta following cyclophosphamide in mice injected with highly metastatic Friend erythroleukemia cells. J Immunother Emphasis Tumor Immunol 13:7-17

98. Rasi G, Silecchia G, Sinibaldi-Vallebona P, Spaziani E, Pierimarchi P, Sivilia M, Tremiterra S, Garaci E (1994) Anti-tumor effect of combined treatment with thymosin alpha 1 and interleukin-2 after 5-fluorouracil in liver metastases from colorectal cancer in rats. Int J Cancer 57:701-705

99. Silecchia G, Guarino E, Sinibaldi-Vallebona P, Pierimarchi P, Restuccia A, Spaziani E, Bernard P, Tuthill C, Garaci E, Rasi G (1999) Efficacy of repeated cycles of chemo-immunotherapy with thymosin alpha1 and interleukin-2 after intraperitoneal 5fluorouracil delivery. Cancer Immunol Immunother 48:172-178

100. Shrivastava P, Singh SM, Singh N (2005) Antitumor activation of peritoneal macrophages by thymosin alpha-1. Cancer Invest 23:316-322

101. Schulof RS, Lloyd MJ, Cleary PA, Palaszynski SR, Mai DA, Cox JW Jr, Alabaster O, Goldstein AL (1985) A randomized trial to evaluate the immunorestorative properties of synthetic thymosinalpha 1 in patients with lung cancer. J Biol Response Mod 4:147158

102. Lopez M, Carpano S, Cavaliere R, Di Lauro L, Ameglio F, Vitelli G, Frasca AM, Vici P, Pignatti F, Rosselli M et al (1994) Biochemotherapy with thymosin alpha 1 , interleukin-2 and dacarbazine in patients with metastatic melanoma: clinical and immunological effects. Ann Oncol 5:741-746

103. Garaci E, Lopez M, Bonsignore G, Della Giulia M, D'Aprile M, Favalli C, Rasi G, Santini S, Capomolla E, Vici P et al (1995) Sequential chemoimmunotherapy for advanced non-small cell lung cancer using cisplatin, etoposide, thymosin-alpha 1 and interferon-alpha 2a. Eur J Cancer 31 A:2403-2405

104. Salvati F, Rasi G, Portalone L, Antilli A, Garaci E (1996) Combined treatment with thymosin-alpha1 and low-dose interferonalpha after ifosfamide in non-small cell lung cancer: a phase-II controlled trial. Anticancer Res 16:1001-1004
105. Rasi G, Terzoli E, Izzo F, Pierimarchi P, Ranuzzi M, SinibaldiVallebona P, Tuthill C, Garaci E (2000) Combined treatment with thymosin-alpha1 and low dose interferon-alpha after dacarbazine in advanced melanoma. Melanoma Res 10:189-192

106. Maio M, Mackiewicz A, Testori A, Trefzer U, Ferraresi V, Jassem J, Garbe C, Lesimple T, Guillot B, Gascon P, Gilde K, Camerini R, Cognetti F; Thymosin Melanoma Investigation Group (2010) Large randomized study of thymosin alpha 1, interferon alfa, or both in combination with dacarbazine in patients with metastatic melanoma. J Clin Oncol 28:1780-1787

107. Stefanini GF, Foschi FG, Castelli E, Marsigli L, Biselli M, Mucci F, Bernardi M, Van Thiel DH, Gasbarrini G (1998) Alpha-1thymosin and transcatheter arterial chemoembolization in hepatocellular carcinoma patients: a preliminary experience. Hepatogastroenterology 45:209-215

108. Cheng SQ, Wu MC, Chen H, Shen F, Yang JH, Cong WM, Zhao YX, Wang PJ (2004) Transcatheter hepatic arterial chemoembolization and thymosin alpha1 in postoperative treatment of hepatocellular carcinoma. Zhonghua Zhong Liu Za Zhi 26:305-307

109. Gish RG, Gordon SC, Nelson D, Rustgi V, Rios I (2009) A randomized controlled trial of thymalfasin plus transarterial chemoembolization for unresectable hepatocellular carcinoma. Hepatol Int 3:480-489

110. Wolf E, Milazzo S, Boehm K, Zwahlen M, Horneber M (2011) Thymic peptides for treatment of cancer patients. Cochrane Database Syst Rev. doi:10.1002/14651858.CD003993.pub3

111. Butler GS, Overall CM (2009) Proteomic identification of multitasking proteins in unexpected locations complicates drug targeting. Nat Rev Drug Discov 8:935-948

112. Joly AL, Wettstein G, Mignot G, Ghiringhelli F, Garrido C (2010) Dual role of heat shock proteins as regulators of apoptosis and innate immunity. J Innate Immun 2:238-247

113. Aguilera R, Saffie C, Tittarelli A, González FE, Ramírez M, Reyes D, Pereda C, Hevia D, García T, Salazar L, Ferreira A, Hermoso M, Mendoza-Naranjo A, Ferrada C, Garrido P, López MN, Salazar-Onfray F (2011) Heat-shock induction of tumorderived danger signals mediates rapid monocyte differentiation into clinically effective dendritic cells. Clin Cancer Res 17:24742483

114. Zhang Y, Calderwood SK (2011) Autophagy, protein aggregation and hyperthermia: a mini-review. Int $\mathrm{J}$ Hyperthermia 27:409-414

115. Tang D, Kang R, Zeh HJ III, Lotze MT (2010) High-mobility group box 1 and cancer. Biochim Biophys Acta 1799:131-140

116. Saenz R, Souza Cda S, Huang CT, Larsson M, Esener S, Messmer D (2010) HMGB1-derived peptide acts as adjuvant inducing immune responses to peptide and protein antigen. Vaccine 28:7556-7562

117. Duthie MS, Windish HP, Fox CB, Reed SG (2011) Use of defined TLR ligands as adjuvants within human vaccines. Immunol Rev 239:178-196

118. Feyerabend S, Stevanovic S, Gouttefangeas C, Wernet D, Hennenlotter J, Bedke J, Dietz K, Pascolo S, Kuczyk M, Rammensee HG, Stenzl A (2009) Novel multi-peptide vaccination in Hla-A2+ hormone sensitive patients with biochemical relapse of prostate cancer. Prostate 69:917-927

119. Institute for Immunology and Thymus Research (2011) Responsible editor Dr. Milan C. Pesic, http://www.thymustherapy.com. Accessed 2 Sept 2011 